\title{
A General Review of Existing Retranslation Study
}

\author{
Yanjie Li \\ School of Foreign Languages, Nanjing University of Posts and Telecommunications, Nanjing, China
}

\begin{abstract}
As a controversial issue in the translation field, the history of translation has witnessed the conflicting debates over whether retranslation is necessary or not. This paper aims to comb the controversial issue by reflecting on the important issues with regard to retranslation. What's more, relevant retranslating strategies are generalized in this paper. Retranslation phenomena spring up for a reason. It is the translators' obligation to justify it, regulate it and thus avoid the chaos of retranslation.
\end{abstract}

Index Terms — retranslation, faithfulness, ideal translation, perspectives, strategies

\section{INTRODUCTION}

Retranslation, as a frequently-occurred phenomenon, has been a controversial issue in the literary translation field. Issues regarding whether retranslating is necessary or why retranslating activities never cease to spring up, seem always simple on the surface. However, retranslating activities is not as simple as it appears to be, on the contrary, it is a rather complicated issue. This paper is mainly concerned with retranslation and, in particular, with the proposal of perspectives to reflect upon the phenomenon of retranslation. Moreover, this paper is an attempt to emphasize the importance of considering about relevant issues of retranslating, and the necessity for further in-depth study of the phenomenon. Therefore, a brief introduction of existing retranslation study would be made. As a result, a clearer picture of from where our research is to proceed may be revealed. In order to set the scene for what is to follow, we need to ask three relevant questions which, we believe, lie at the root of any attempt to understand the phenomenon of retranslation and, if such is our goal, improve the work of the translator.

In consequence, in order to clarify the confusion of retranslation status and help us gain a better understanding towards retranslation phenomenon, in the following parts, we are going to respectively respond to three questions as follows:

A. Is "Faithfulness" to the Original Possible?

B. What Are the Characteristics of Literary Translation?

C. Does There Exist the "Ideal Translation" in Literary Translation?

Undoubtedly, it is easy to figure out that these questions are fraught with ambiguity and that the answers to them, not surprisingly, are far from satisfactory. On top of this, we are to center on the discussion of the only theme of retranslation, which will recur in different guises throughout the paper, although we probably may not mention it directly.

\section{Delimitation OF Retranslation}

In this part, before we explore into these questions, it is extremely necessary for us to clarify the ideas borne in mind of what translation is about. Accordingly, at the very beginning of this part, we had better have a general look of the definitions of translation so that we can clear our confusions in mind.

Catford (1965, p.20)) thus defines translation as follows: "The replacement of textual material in one language (SL) by equivalent textual material in another language (TL)." Then Catford (1965, p.21) further argues as what follows: "The central problem of translation practice is that of finding TL translation equivalents. A central task of translation theory is that of defining the nature and translation equivalence." Needless to say, Catford stresses that the essential thing of translation is to seek for "TL translation equivalents", which, of course, is highly advocated by most translation scholars of translation field.

However, Ian F. Finlay (1971, p.1) expresses his viewpoints of what makes a translation in a quite different way. Finlay contends that "A translation must be defined as a presentation of a text in a language other than that in which it was originally written." What's more, Finlay (ibid) holds that: "Normally, it is universally accepted that any translation worthy of the name must reproduce the full sense of the original, omitting nothing and adding nothing." Another point of Finlay worthy of noticing is stated as follows: "Ideally, the translation should give the sense of the original in such a way that the reader is unaware that he is reading a translation." (Finlay, 1971, p.2) From Finlay's above statements we can clearly get the idea of "reproducing the full sense of the original, omitting nothing and add nothing" and that "giving the sense of the original" even leads to the situation that "the reader is unaware that he is reading a translation". An ideal picture of translation is vividly described. There is no doubt that it is every translator's dream to achieve that 
goal. However, it always remains the highest aim for any translators to arrive at.

Right up to the end of the 1970s, definitions of translation can be described as variations on the central theme of "equivalence". In Nida and Taber (1969, p.12) we find: "Translating consists in reproducing in the receptor language the closest natural equivalent of the source language message, first in terms of meaning and secondly in terms of style." In the sense of "equivalence", the viewpoints of Catford and Nida have something in common, yet Nida explain it further and specifically declares that the equivalence should be of "first in terms of meaning and secondly in terms of style". So in this sense, Nida's points of view sound more reasonable and convincing.

From the above-mentioned discussions we may find out that the core these definitions possess lies in the translator's effort to attain the aim of the closest natural equivalent to the original. In other words, the criterion of translation in the translator's mind is whether a translation is "faithful" to the original or not. Since this question is in close relation with retranslation, in the next section we will discuss it separately. And before we go further, we would like to provide a definition of He Lin (1998, p.43) as follows: "In a philosophical sense, translation is a communication between the interpreter and the text, which contains the procedure of understanding, interpretation, apprehension and transformation, etc.. The translated text is the result of the objectivization. It is the condensation and fulfillment of the communication between the interpreter and the text. And the relationship between the translation and the text is similar to that between interpretation and implication, or writing and logos."

And here, the author would like to offer one definition of translation from the philosophical hermeneutic perspective: "Translation is inevitably bound up with understanding, interpretation, and recreation. During the process of translation, the translator himself as a reader continually adjusts his prejudices to the text and carries out a conversation with the text. Hence finally he removes the alienation that is brought about by temporal distance and attains the "fusion of the horizons', so to speak, he accomplishes the product as a translation."

Aside from the above-mentioned clarifications of various definitions on translation, we feel it necessary to distinguish some translation terms according to Roger and T. Bell, (1991, p.13), which are as follows:

a. translating: the process( to translate; the activity rather than the tangible object);

b. a translation: the product of the process of translation (i.e. the translated text);

c. translation: the abstract concept which encompasses both the process of translating and the product of that process.

As a result, when we later mention the concept of retranslation in the following parts, what we mean is similar to the above-mentioned. Due to the complexity of retranslation, we just provide a loose definition here: retranslation refers to the translations of the same text. As a matter of fact, we cannot provide a comprehensive and accurate definition here, for no consensus with regard to it has been reached among translation scholars. Hence the author deems it preferable to leave the definition open.

To make it clear, we should add up one point here, if we mention the "text", it refers to "the original", namely the original text. The reason why we adopt the "text" instead of the "original" at times is due to the ontological standpoint we take in the current paper. Now, since we have already made necessary clarifications in the previous discussion, we have to come back to the question we previously put forward at the beginning of this paper: is "faithfulness" to the original possible?

\section{PersPectives On Retranslation}

\section{A. Is "Faithfulness" to the Original Possible?}

Ever since human beings were first engaged in the act of translation, debates on what should be done in translation began. However different their diction may be at first sight, these debates basically center on one issue: whether a translation is faithful to the original or not? As to this puzzle, Theodore (1968, p.54) generalizes a list of the various representative views toward translation in The Art of Translation as follows:

a. A translation must give the words of the original.

b. A translation must give the ideas of the original.

c. A translation should read like an original work.

d. A translation should read like a translation.

e. A translation should reflect the style of the original.

f. A translation should possess the style of the translation.

g. A translation should read as a contemporary of the original.

h. A translation should read as a contemporary of the translation.

I. A translation may add to or omit from the original.

j. A translation may never add to or omit from the original.

$\mathrm{k}$. A translation of verse should be in prose.

1. A translation of verse should be in verse.

From the views listed above we may realize that those diametrical principles reveal the translator's dilemma: they are confronted with options. Regardless of how hard they try to improve their work of translation, they are destined to feel depressed while they are facing those choices, in other words, they have to make hard decisions while translating: they have to either oppose them or make possible compromises.

If we trace back to the history of translation theory, we may notice that three "laws of translation" which Alexander 
Tytler (1978, p.54) formulates in his Essay on the Principles of Translation as follows:

I. That the translation should give a complete transcript of the ideas of the original work.

II. That the style and manner of writing should be of the same character with that of the original.

III. That the translation should have all the ease of the original composition.

In explaining the first of these general rules, Tytler (1978, p.17) emphasizes as such: "it is indispensably necessary, that he (the translator) should have a perfect knowledge of the original, and a competent acquaintance with the subject of which it treats." Tytler's points of view make great sense: a perfect knowledge of the original and a competent acquaintance with the subject would ensure a translator's translating process smooth and certainly the quality of translation would be guaranteed with no doubt.

Furthermore, if we explore deeper into the root of the issues of the "what the translator should do" and the "laws of translation" and the like, we may say, they would all focus on one issue: is "faithfulness" to the original possible? Dryden (Snell-Hornby, 1988, p.11) compares translation to "dancing on ropes with fettered legs" and long time ago we have the old axiom "traduttore-traditore". In the West academic translation field, translation by nature is in close connection with the history of the translating of The Bible. Hence the holy text determines a translator's attitude, so to speak, the sacred text, The Bible, must be translated with the utmost fidelity. Accordingly, the translator's complex of "faithfulness" comes into being in the atmosphere of the worship of God.

Moreover, the translating of The Bible provides a persuasive proof for the possibility of translation: since even the words of God can be translated (regardless of whether it conforms to "faithfulness" or not), then, is there anything that cannot be translated? However, the real problem arises: can the translation and the text (original) have the identical truth, so to speak, even if the translation can attain the aim of "faithfulness", can this so-called "faithfulness" reach the "truth" of the text? Hence the question of the relativity of translation comes up.

In the above paragraphs we have examined what most translators argue about the problem of "faithfulness". Although it seems to be a cliché with regard to translation, we still think it necessary to mention it again. What's more, we shall further clarify it in the following parts.

\section{B. What Are the Characteristics of Literary Translation?}

"Literary translators", writes Finlay (1971, p.45), are "translators of all types of fiction and covers such categories as novels, plays, poetry, film scripts and the like, as well as, in many cases, biographies, travel books and similar basically non-technical types of non-fiction."

In China, many literary translators, such as Xu Yuanchong (1999), holds that literary translation is an art and recreation. There are also other similar voices in the field of translation. Xie Tianzhen (1998) maintains that literary translation is a productive, cross-cultural betrayal. Luo Xinzhang (1995) describes the act of translation as "the productive translation", which means that the work of the translator belongs to a second creation different from that of the writer. Wang Kefei (1996) even argues that the truth of the translation lies in that it has the single truth but it has to be presented by multiple means of expressions. These voices on literary translation reveal an identical truth that literary translation calls for requirements or stresses different from technical translation work. Therefore, we will make an attempt to analyze the characteristics that literary translation possesses in the following parts.

Another translation scholar Fang Ping (1998, p.124) has put forward the following ideas: literary translation possesses two characteristics, namely subordination and subjectivity. It is always the case that is confronted by the translation. Therefore, due to the commitment to make a bridge between different cultures, literary translators take "fidelity to the text" as their major task. In the previous section we have discussed the problem of fidelity, which is in connection with the claim of "equivalence". Roger and T. Bell (1991, p.6) argue as such: "It is apparent, and has been for a very long time indeed, that the ideal of total equivalence is a chimera." However, we may ask: why does this take place? The subordination of literary translation determines that the translator must respect the text. However, not all the translators can realize that subordination is just one aspect of literary translation. If it is over-exaggerated, literary translation may fall into a simple work of copy and lose its necessary significance. To be frank, this is always the case with translation: misunderstandings and partial prejudices toward literary translation all arise from that.

As a matter of fact, during the process of translating, the translator is always switching to and fro between subordination and subjectivity, attempting to search for the best combination of the two extreme poles. Subordination and subjectivity make compensation for each other and work together. Without subordination, a translation cannot be regarded as translation at all. On the other hand, literary translation will not deserve its title if it lacks the function of the role of subjectivity.

In addition, the art of translation cannot be neglected in literary translation. Due to the above reasons we attach great importance to subjectivity of literary translation. In consequence, literary translation, with the same character as the other artistic forms, becomes a creative work. It is of great importance to comprehend the characteristics possessed by literary translation, for it illustrates the phenomenon of retranslation of literary works to some extent.

Then, on the basis of the analysis of the characteristics of literary translation, we would be prepared to deal with another question in the following part: does there exist the "ideal translation" in literary translation?

\section{Does There Exist the "Ideal Translation" in Literary Translation?}

With the development of the economy, translation activities reach a climax in the twentieth century, the so-called 
"age of translation". Many famous foreign literary works are to be translated over and again. On the one hand, the boom of retranslation actions means the prosperity of translation. On the other hand, this kind of concentrated retranslation activities has brought about quite a number of problems. As a result, translation scholars are deeply concerned about this issue and they carry out the debates over retranslation phenomenon in order to cope with this in a proper way. Some translators are in favor of the activities of retranslation while others disagree with actions like that. Those who show approval for retranslation phenomenon hold faith in that it is reasonable and possible to allow the existence of varied versions of translation of one literary text. On the contrary, as to those who disagree with it, they just believe that there is only one-direction of true meaning, other than the only true meaning of the original, the author's meaning, other alternatives of interpretations might cause confusion and chaos in understanding of the text as well as the order of translation. Needless to say, however their attitudes seem to be different at first sight, the issues they discuss are all centered on one theme: does there exist the "ideal translation" in literary translation?

According to the viewpoints of Xu Jun (1991), the so-called "ideal translation" must contain three levels of connotation. First, an "ideal translation" must achieve its perfection both in understanding and expression, without any mistakes in understanding and any blank in interpretation. Not only can it be equivalent to the text in content, but also it can rival with the text in form. Accordingly, there remains no possibility and necessity for retranslation. Secondly, the "ideal translation" also has the meaning of "being immortal", so to speak, it can last beyond time and space. Regardless of which age it is, the "ideal translation" is to be adored as classics. Hence there is no necessity to make any correction or adjustment for the translation with the changes of times, language, or readers' aesthetic taste. The "ideal translation" will be the everlasting model. Thirdly, the "ideal translation" also includes the meaning of "the perfect model". From my point of view, when confronted with a text, it is natural that different translators may have different understandings and expressions for the text, therefore, different translations regarding the same text seem to be reasonable. In this sense, an "ideal translation" may remain as a relative concept, for it is questionable to set an absolute standard for what might be the "ideal translation". Therefore, it is reasonable to make deduction that the activities of retranslation are justified and reasonable.

\section{REleVAnt Retranslating StRATEgies}

In this section, the author intends to briefly introduce relevant retranslation strategies so as to broaden the translators' horizon in understanding what underlies retranslation. Accordingly, four strategies with regard to retranslation are to be generalized, among which one strategy is put forward by the author. These strategies (Charles, 1998) run as follows:

a. Corrective translation. It refers to the retranslation of a work already existing in a bad or faulty translation in order to provide the target language receptor with a more faithful reproduction of the original. According to the above-mentioned, it is easy to know that the goal of corrective translation is to make a better translation of a work that has already existed in the target language in an imperfect form.

b. Critical translation. It refers to the retranslation of a literary work already extant in a translation free of errors and "acceptable" in order to shed new interpretational light on the original work. By definition, it is obvious to see that the goal of critical translation is to retranslate a work already extant in an acceptable form in the target language, in order to present the reader with a valid interpretation of the original work that the earlier translations do not possess.

c. Proselytizing translation. It refers to the retranslation of a work already existing in an acceptable form in the target language, with the intent of emphasizing its special meaning for a particular, well-defined group of receptors via an interpretation of the text according to the customs, ideas, or world-views of said group. It is worth mentioning that the goal of proselytizing translation is to retranslate a work already extant in an acceptable form in the target language in order to actualize its message for a particular group of readers.

d. Neoconceptual translation. This strategy, put forward by the author, refers to the retranslation of a work already existing in an acceptable form in the target language, with the intent of eliminating gender discrimination or certain violent inclination reflected in the language of translation. By definition, the goal of neoconceptual translation is to purify the language of translation so as to avoid the language pollution in translation.

It must be pointed out that these translation strategies must unavoidably have something in common. As a matter of fact, it is hard to draw a sheer borderline between them. Needless to say, each strategy has its own right to survive and each translator is free to take his own options.

\section{CONCLUSION}

Andrew Chesterman $(1997,184)$ argues as such: “As readers, we perceive a something, and we then try to interpret this something, to understand it. But the whole process is a relative one. Perfect understanding like perfect clarity, is a relative idea." Since "perfect understanding" is just a relative idea, the "ideal translation" is also a relative one. Therefore, the "ideal translation" is after all an ideal that does not exist in reality. Some scholars, such as Xu Jun (1998), Fang Ping (1998), and Xie Tianzhen (1998), have expressed similar viewpoints.

The characteristics that literary translation possesses determine that the "ideal translation" does not exist in literary translation. The constant retranslating recurs for a reason, and different retranslating strategies lead to retranslations for different purposes, which has become a consensus shared by most translators. However, we may find that the above 
discussion only proceeds from the level of language, which obviously lacks a deeper exploration into retranslation. This is always the case with the existing retranslation study: as to what underlies the retranslation phenomenon, how to understand it from a macroscopic and speculative perspective with reference to philosophy, the translators rarely discuss. Accordingly, we are committed to undertaking the investigation within the framework of philosophy, which, in my opinion, would be hermeneutics, the philosophy of interpretation and understanding. To fully understand and interpret retranslation, further study will be necessary and indispensible.

\section{REFERENCES}

[1] Catford, J. C. (1965). A Linguistic Theory of Translation. London: Oxford University Press.

[2] Charles S. Kraszewski. (1998). Four Translation Strategies Determined by the Particular Needs of the Receptor. Lewiston: The Edwin Mellen Press.

[3] Chesterman, Andrew. (1997). Memes of Translation. Amsterdam/Philadelphia: John Benjamins Publishing Company.

[4] Fang Ping. (1998). Bu cunzai lixiang de fanben (No Ideal Translation Exists). Fanyi sikaolu (Contemplation on Translation). Wuhan: Hubei jiaoyu chubanshe (Hubei Education Press), 124-132.

[5] Finlay, Ian F. (1974). Translating. Edinburgh: The English Universities Press Limited.

[6] He Lin. (1998). Tantan fanyi (On Translation). Fanyi sikaolu (Contemplation on Translation). Wuhan: Hubei jiaoyu chubanshe (Hubei Education Press), 42-45.

[7] Luo Xinzhang. (1995). Shi yizuo (Interpretation of Translation). Zhongguo fanyi (Chinese Translators Journal) 02, 9-12.

[8] Nida, Eugene A. \& Taber, Charles R. (1969). The Theory and Practice of Translation. Leiden: Brill.

[9] Roger and Bell, T. (1991). Translation and Translating: Theory and Practice. London: Longman Group UK Limited.

[10] Savory, Theodore. (1968). The Art of Translation. London: Cape.

[11] Snell-Hornby, Mary. (1988). Translation Studies: An Integrated Approach. Amsterdam/Philadelphia: John Benjamins Publishing Company.

[12] Tytler, Alexander Fraser \& Woodhouselee, Lord. (1978). Essay on the Principles of Translation. J.F. Huntsman (ed.). Amsterdam: Benjamins.

[13] Wang Kefei. (1996). Guanyu fanyi de zhexue sikao (Philosophical Contemplation on Translation). Waiyu jiaoxue yu yanjiu (Foreign Language Teaching and Research) 04, 495-505.

[14] Xie Tianzhen. (1998). Wenxue fanyi: yizhong kuawenhua de chuangzaoxing panni (Literary Translation: a Trans-cultural Creative Rebellion). Fanyi sikaolu (Contemplation on Translation). Wuhan: Hubei jiaoyu chubanshe (Hubei Education Press), 206-217.

[15] Xu Jun. (1994). Chongfu • chaoyue - mingzhu fuyi xianxiang pouxi (Repetition - Surpassing-Analysis on Retranslation of Masterpiece). Zhongguo fanyi (Chinese Translators Journal) 03, 2-5.

[16] Xu Jun. (1998). Fanyi bu keneng you dingben (Fixed Translation Is Impossible). Fanyi sikaolu (Contemplation on Translation). Wuhan: Hubei jiaoyu chubanshe (Hubei Education Press), 133-138.

[17] Xu Yuanchong. (1999). Yixue yao ganwei tianxia xian (Translation Needs Bold Attempt). Zhongguo fanyi(Chinese Translators Journal) 02, 8-9.

Yanjie Li obtained her M.A. degree in Translation Theory and Practice, one branch of Applied Linguistics from School of Foreign Languages, South Central University of China in 2001. She is currently a lecturer of the School of Foreign Languages, Nanjing University of Posts and Telecommunications in China. Her primary research interests cover Translation Studies, English teaching methodology, and Teaching English to Speakers of Other Languages. 